\title{
Notes on Pandemic-Era Screendance-making
}

\author{
Rebecca Salzer, University of Alabama
}

Keywords: screendance, lockdown, pandemic-era, screen-based, digital adaptation, virtual dance

The dance world's abrupt and involuntary convergence on screens during lockdown has generated a flood of new dance content online. In addition to broad sharing of previously unseen dance recordings, dance artists unaccustomed to creating for screens have made the shift as a way to stay active, fulfilled, visible, and solvent. As an experienced screendance-maker, I hoped this moment might legitimize or even valorize screendance practices and practitioners for the mainstream dance world. Like so much else in 2020, this has not quite gone as I expected. Below is a discussion of trends in recent screen-based dance and the works that exemplify them.

A common characteristic of many dances made since lockdown is the use of screens to erase physical, temporal, and even generational distance. Often, the visual anchor is one continuous phrase of movement shared between dancers, performed across seasons, or placed in different locations. ${ }^{1}$ One of the first iterations of this was the Alvin Ailey American Dance Theatre company's collective performance of the "Buked" section from Revelations. ${ }^{2}$ It brought the new thrill (now commonplace) of seeing virtuosic artists close up, without lights, costumes, and make-up, and joined in their homes by children and pets. The widely shared video was like an affirmation of faith for the newly diasporic dance community, relocating sacred choreography to mundane spaces and demonstrating that even when displaced from the studio and the theatre, our bodies hold the artform. Although it preceded the pandemic by six years, Mitchell Rose's film Globe Trot, which features 50 performers in 23 countries packed into a span of less than 5 minutes, modeled this space, time, and distance-collapsing concept, and now plays like an anthem for Covid-times. Realizing this, in March 2020, Rose generously shared a sort of how-to guide for his style of "hyper matchcut" filmmaking ${ }^{3}$ via a closed Dance Professors Online Transition Group Facebook page for dance educators hurriedly pivoting to virtual everything. ${ }^{4}$

Janet Wong took an imaginative and markedly different approach to collapsing multiple solo clips into one work in her edit of the Bill T. Jones/Arnie Zane work, 
Continuous Replay: Come Together, ${ }^{5}$ live-streamed on November 19, 2020. Employing an architectural structure of moving split screens on a grid-like background, Wong guided us through a virtual installation of 44 video solos. The effect felt strangely cold and technical, given that the performance was a coming together of and love song to multiple generations of the company. But, by letting individual videos drift in and out of the frame instead of employing quick cuts, Wong succeeded in preserving the continuousness of the piece's title.

Looking at work as visually complex as Continuous Replay has led me to wonder if the pandemic is altering our aesthetics. I certainly have more neurological stamina for the multiple images and sounds of Zoom meetings, classes, and gatherings than I did in March 2020. Could we possibly be moving toward a collective preference for art that harnesses this multiplicity? Paradoxically, even as I seem better able to process multiple images within one frame, I have also noticed that camera movement and multiple camera angles in pre-pandemic dance films now seem strangely artificial compared to the current, static, single-camera images of dancers in living rooms and gardens.

These same living rooms and gardens constitute another challenge for pandemic dance-making. Even pre-Covid, dance-makers often misunderstood the way the camera lens inverts spatial geometry, choosing locations that in-person seemed to provide a sweeping and idyllic background but detracted from the movement when on-camera. Although Doris Humphrey wrote about stage space rather than screen space, she described the problem aptly in her mid-1950s text The Art of Making Dances:

The student should be led away from his understandable feeling that dancing is movement of the body and can be placed just anywhere that is convenient in the space at his command. This introspective concentration on the movement has been instilled in him by years of class work, in which the only space consideration was to find room enough to work without interfering with other people. ${ }^{6}$

The issue is compounded when dancers move from the limits of stage space to performing anywhere and everywhere, and compounded again when they record themselves with no external eye. One glorious exception is the opening clip of Alonzo King LINES Ballet's There is No Standing Still Part 1, released in June 2020.7 In the clip, Adji Cissoko, standing in a grove of tall trees, reaches three of her own tall limbs to the sky in perfect harmony with her surroundings. The image is also a balm for its locked-down audience, allowing us to experience the freedom and strength of Cissoko's body in concert with the natural world. It is a rare moment in which movement and location are not juxtaposed or in competition, but contribute to a unified vision.

With respect to my hoped-for convergence between mainstream dance-makers and the screendance community, the results have been mixed. Dance On! An Evening with the Mark Morris Dance Group, which premiered on May 28, 2020, was preceded on May 26 by Marina Harss's feature in the New York Times titled, "The Pragmatist's Progress: Mark 
Morris Adapts to Creating Online." ${ }^{18}$ Morris, I thought, would have his pick of screendance collaborators. But, Harss's feature revealed that instead of reaching out for expertise in screendance or even more generally to professional cinematographers and editors, Morris instead relied on his music director, Colin Fowler, who "taught himself the editing program Final Cut Pro after the lockdown began." During the second iteration of Dance On!, live-streamed on November 12, an audience member questioned why Morris found Fowler to be the "collaborator of choice" in the role of film editor. He responded that Fowler is a "jack of many trades," a "tech queen-nerd," and has a music degree from Julliard. Even though I wholeheartedly support Fowler and Morris's experimentation in this new medium, their disregard for an entire field of artistic expertise is disappointing. Can you imagine Morris taking similar pride in declaring that one of his dancers had taught themselves to play the piano in order to accompany a performance?

Dance On! Parts 1 and 2, unsurprisingly, are recognizable as early experiments in digital editing. Morris and Fowler lean heavily on effects, exploring the many tools the medium provides to manipulate movement in time and space, in pronounced contrast to their often spare and elegant work for live performance. A welcome exception is Morris's solo Offertorium, performed by Lauren Grant as part of Dance On! Part $2,{ }^{9}$ in which the compositional integrity of Morris's movement and Schubert's music carry over to the video edit.

More heartening has been the inclusion of screendance collaborators in the Virtual Commissions from Works and Process at the Guggenheim, including Ben Stamper, whose Notes on Gathering with Andrea Miller boasted the most stunning cinematography of the series at the time of this writing. ${ }^{10}$ Donald Byrd's Solanum Dulcamara, created with Teri Jeanette Weikel, and filmmaker Luke Wigren also stands out for its masterful use of available materials during a lockdown, layering historical video with intimate, contemporary shots of both Byrd and Weikel to communicate the complexity of relationships and art-making.

I do not mean to imply that dancers should stay in their lane and leave the cinematography and editing to the professionals. I actually believe quite passionately that dance artists have a singular vision for how their work should be translated to screens, that they should acquire the requisite skills to do so, and that the field's tendency to outsource this translation is one of the major reasons dance has not yet fully realized the potential of screen space. But, dance-makers new to screen-based work can also educate themselves, honoring and learning from skilled practitioners and more than a century of dance filmmaking history and practice. It is a fine line, but one that can lead us out of this time better equipped for a world that again includes live performance. 


\section{Biography}

Rebecca Salzer, Associate Professor of Dance and Director of the Collaborative Arts Research Initiative at The University of Alabama, is an intermedia dance artist and educator. Her work for the stage has been seen in Chicago, Los Angeles, San Diego, and San Francisco, where she directed Rebecca Salzer Dance Theater for a decade. Her award-winning films and videos have been programmed in national and international venues and on public affiliate television stations KQED, KPBS, and WTTW. Salzer holds a B.A. in Humanities from Yale University and an M.F.A. in Dance Theatre from the University of California, San Diego, where she was a Jacob K. Javits Fellow. She also serves as Project Director for the Dancing Digital Project, supported by the National Endowment for the Humanities (dancingdigital.org), which works toward creating and facilitating more centralized, accessible, equitable, and forward-thinking dance resources online.

Email: rsalzer@ua.edu

Website: http://www.rebeccasalzer.com

\section{Notes}

'Two examples are Redha Medjellekh's One Year, featuring Calvin Royal III, which extends one continuous movement phrase through multiple seasons and Derek Brockington and Alexandra Hutchinson's Dancing Through Harlem, which extends one continuous movement phrase across multiple performers and locations.

2 “Ailey Dancers Perform an Excerpt from 'Revelations' ('Buked' Section), Together While Apart" (2020) by Miranda Quinn.

${ }^{3}$ Also including Rose's works Exquisite Corps, and And So Say All of Us.

${ }^{4}$ Rose, "ATTENTION TELE-TEACHERS"

5 "Continuous Replay: Come Together" (2020) by Arnie Zane.

${ }^{6}$ Humphrey, 72.

7 "There Is No Standing Still, Part I" (2020) by Alonzo King.

${ }^{8}$ Harss, C1.

9 "Dance On! An Evening with the Mark Morris Dance Group Part 2" (2020) by Mark Morris. 
${ }^{10}$ Ben Stamper might find "screendance-maker" too narrow a term to describe his cinematic expertise. I use the term here to acknowledge his specific experience in this area.

\section{References}

Ailey Dancers Perform an Excerpt from 'Revelations' ('Buked' Section), Together While Apart. Concept by Miranda Quinn. Ed. Danica Paulos. 2020. YouTube.

https://www.youtube.com/watch?v=gEFW5JznwOY\&ab_channel=AlvinAileyAmerican DanceTheater

Continuous Replay: Come Together. Chor. Arnie Zane. Ed. Janet Wong. 2020. YouTube. https://www.youtube.com/watch?v=ZfrrQOeooZU\&ab_channel=BillT.JonesArnieZane Company

Dance On! An Evening with the Mark Morris Dance Group Part 2. Chor. Mark Morris. Ed. Colin Fowler. 2020. YouTube. https://www.youtube.com/watch?v=Z66bKW_Hv1U\&ab_ channel=MarkMorrisDanceGroup

Dancing Through Harlem. Dir. Derek Brockington and Alexandra Hutchinson. Chor. Robert Garland. 2020. YouTube. https://www.youtube.com/watch?v= H1Ybm6ToJBI\&ab_channel=DanceTheatreofHarlem

Harss, Marina. "The Pragmatist's Progress: Mark Morris Adapts to Creating Online." The New York Times, 26 May 2020. C1.

Humphrey, Doris. "Chapter 9: Design Part 4." The Art of Making Dances. New Jersey: Princeton Book Co., 1987.

One Year 2019-2020. Dir. Redha Medjellekh. Perf. Calvin Royal III. 2020. YouTube. https://www.youtube.com/watch?v=nl1bzPsyynA\&ab_channel=AmericanBalletTheatr e

Rose, Mitchell. 2020. "ATTENTION TELE-TEACHERS OF DANCE/FILM/ART. Facebook, March 18, 2020. https://www.facebook.com/MitchellRose/posts/10163112065415371

There Is No Standing Still, Part I. Dir. Robert Rosenwasser. Ed. Phillip Perkins. Chor. Alonzo King. Mus. Edgar Meyer. 2020. YouTube. https://www.youtube.com/watch?v=vC67mWXKW5w\&ab_channel=AlonzoKingLINES Ballet 